\title{
Acute kidney injury in severe trauma assessed by RIFLE criteria: a common feature without implications on mortality?
}

\author{
Ernestina Gomes ${ }^{1}$, Rui Antunes ${ }^{1 *}$, Cláudia Dias², Rui Araújo ${ }^{1}$, Altamiro Costa-Pereira ${ }^{3}$
}

\begin{abstract}
Background: Acute kidney injury (AKI) has been hard to assess due to the lack of standard definitions. Recently, the Risk, Injury, Failure, Loss and End-Stage Kidney (RIFLE) classification has been proposed to classify AKI in a number of clinical settings. This study aims to estimate the frequency and levels of severity of AKI and to study its association with patient mortality and length of stay (LOS) in a cohort of trauma patients needing intensive care.

Methods: Between August 2001 and September 2007, 436 trauma patients consecutively admitted to a general intensive care unit (ICU), were assessed using the RIFLE criteria. Demographic data, characteristics of injury, and severity of trauma variables were also collected.

Results: Half of all ICU trauma admissions had AKI, which corresponded to the group of patients with a significantly higher severity of trauma. Among patients with AKI, RIFLE class R (Risk) comprised 47\%, while I (Injury) and $F$ (Failure) were, 36\% and 17\%, respectively. None of these patients required renal replacement therapy. No significant differences were found among these three AKI classes in relation to patient's age, gender, type and mechanism of injury, severity of trauma or mortality. Nevertheless, increasing severity of acute renal injury was associated with a longer ICU stay.
\end{abstract}

Conclusions: AKI is a common feature among trauma patients requiring intensive care. Although the development of AKI is associated with an increased LOS it does not appear to influence patient mortality.

\section{Introduction}

Acute Kidney Injury (AKI) affects 5 to $7 \%$ of all hospitalized patients. In the ICU population, this syndrome is common with an incidence of 1 to $25 \%$, depending on the criteria used for definition, and is associated with mortality rates of 50 to $70 \%$ [1-6]. For many decades, diverse definitions for AKI have been used, which explains the difficulty in understanding the wide interstudy variations. AKI is a complex disorder with multiple etiologies, different clinical manifestations, and outcomes ranging from minimal elevation in serum creatinine to anuric renal failure.

In response to the need for a common meaning for AKI, because AKI has been, over the last few decades the focus of extensive clinical research efforts, the Acute

\footnotetext{
* Correspondence: ruiavantunes@gmail.com

${ }^{1}$ Unidade de Cuidados Intensivos Polivalente, Hospital de Santo António, Centro Hospitalar do Porto, 4099 - 001 Porto, Portugal
}

Dialysis Quality Initiative Group, a panel of international experts in nephrology and critical care medicine, developed and published a set of consensus criteria for a uniform definition and classification of AKI [7] (table 1 shows the RIFLE classification). These criteria, which make up the acronym 'RIFLE', classify renal dysfunction according to the degree of impairment present: there are three grades of severity - risk (R), injury (I), and failure (F), and two outcome classes - sustained loss (L) of kidney function and end-stage kidney disease (E). RIFLE criteria, which have the advantage of providing diagnostic definitions for a stage when kidney injury can still be prevented $(\mathrm{R})$, have been tested in clinical practice and seem to be at least congruent with the outcome of a patient with AKI [8-10]. This system has several advantages. It appears sensitive to the early changes in kidney function, allows monitoring of progression of AKI and could function as a robust instrument to discriminate clinical relevant outcomes. The RIFLE classification has
() Biomed Central

C 2010 Gomes et al; licensee BioMed Central Ltd. This is an Open Access article distributed under the terms of the Creative Commons Attribution License (http://creativecommons.org/licenses/by/2.0), which permits unrestricted use, distribution, and reproduction in any medium, provided the original work is properly cited. 
Table 1 Risk, Injury, Failure, Loss and End-stage Kidney (RIFLE) classification [7].

\begin{tabular}{ccc}
\hline Class & Glomerular filtration rate criteria & Urine output criteria \\
\hline Risk & Increased SCreat $\times 1.5$ or GFR decrease $>25 \%$ & $<0.5 \mathrm{ml} / \mathrm{kg} / \mathrm{hour} \times 6 \mathrm{hours}$ \\
Injury & Increased SCreat $\times 2$ or GFR decrease $>50 \%$ & $<0.5 \mathrm{ml} / \mathrm{kg} / \mathrm{hour} \times 12 \mathrm{hours}$ \\
Failure & Increased SCreat $\times 3$ or GFR decrease $>75 \%$ or SCreat $\geq 4 \mathrm{mg} / \mathrm{dl}$ & $<0.3 \mathrm{ml} / \mathrm{kg} / \mathrm{hour} \times 24$ hours, or anuria $\times 12$ hours \\
Loss & Persistent acute renal failure $=$ complete loss of kidney function $>4$ weeks \\
End-stage kidney disease & End-stage kidney disease $>3$ months \\
\hline
\end{tabular}

been evaluated and validated in numerous clinical studies enrolling critically ill patients namely post-operative patients and burned patients, and found to be a valid tool for the precocity of the diagnosis and staging of AKI, having predictive ability for mortality [11-16].

A few studies in trauma patients have shown that the incidence of renal failure varies from less than $0.1 \%$ to $18 \%$, with an associated mortality ranging from 7 to $83 \%$ [12,13,17-19]. In particular, the study by Bagshaw and a study by Yuan were able to show the application of the RIFLE criteria to characterize AKI in a population of patients with trauma [12,19].

Keeping in mind the relevance of this issue and the limited data available in the literature, we aimed to characterize AKI using the RIFLE classification and relate it to ICU length of stay (LOS), hospital LOS, and mortality in a cohort of severe trauma patients that needed Intensive Care. Preliminary results of this study were published elsewhere [20].

\section{Materials and methods}

We studied all trauma patients admitted to the ICU between August 2001 and September 2007 at Hospital de Santo António. This university hospital is a level 1 trauma centre in the city of Porto in northern Portugal, with about 1800 trauma patients per year [21].

Epidemiology and severity data including age, gender, mechanism of injury, injury severity score (ISS), revised trauma score (RTS), Trauma and Injury Severity Score (TRISS) [22], and length of stay were obtained from the prospective trauma registry. TRISS methodology is one of the most used severity methodologies. It uses anatomic severity (ISS) and physiological severity (RTS), age and type of trauma to arrive to a probability of survival. Clinical charts were reviewed for urine output, daily serum creatinine, intracranial hypertension and Simplified Acute Physiology Score (SAPS II). Patients with chronic kidney disease and a second admission were excluded. Chronic kidney disease was defined using the definition of the National Kidney Foundation [23].
Intracranial hypertension was defined as persistent intracranial pressure above $20 \mathrm{mmHg}$. Renal trauma was defined as direct trauma to the kidney resulting from the accident.

Patients were classified into classes R (Risk), I (Injury) and $F$ (Failure), according to the highest RIFLE class reached during their ICU stay. The RIFLE class was determined according to the worst degree of either glomerular filtration rate (GFR) criteria (according to the creatinine values and never used the GFR per se) or urine output criteria. For patients without serum creatinine baseline historical data, we determined a baseline serum creatinine level using the Modification of Diet in Renal Disease equation (MDRD) [24]. When baseline serum creatinine is unknown, current recommendations allow you to estimate this value using the MDRD equation, assuming a glomerular filtration ratio of $75 \mathrm{ml} /$ $\mathrm{min} / 1.73 \mathrm{~m}^{2}$. Recently, Bagshaw and collaborators validated the use of this equation to assess RIFLE criteria [25].

We measured outcomes as the use of renal replacement therapy, length of ICU and hospital stay, and mortality. We divided mortality into ICU mortality, if it occurred during ICU stay and Hospital mortality if it occurred during the rest of Hospital stay. If mortality occurred after hospital discharge it was not considered. Moreover we divided mortality into early ( 2 or less days) and late (more than 2 days).

Continuous variables were expressed as means \pm standard deviations for normal distributed variables and medians and inter-quartile range (IQR) otherwise. The categorical variables were expressed as absolute and relative frequencies. Pearson Chi Square was used to analyze categorical data. ANOVA and T test were used for variables with normal distributions, and Mann Whitney or Kruskall Wallis for other data. A P-value $<0.05$ was considered statistical significant. Analysis was performed with the statistical software package SPSS 15.0 for Windows. 


\section{Results}

In total, 436 trauma patients admitted in ICU were studied. Patients characteristics, outcomes, and comparison between AKI and no AKI groups are summarized in table 2 and 3 . All the patients were mechanically ventilated. Eighty percent of patients were male, with a median age of 37 years (IQR 23-55). The majority had blunt trauma (95\%) caused by road traffic accidents (67\%). Mean ISS and RTS was $27.3(\mathrm{SD}=11.4)$ and $5.7(\mathrm{SD}=$ $1.4)$, respectively. Renal trauma had an incidence of $2.5 \%$ in our cohort (11 patients), with a similar distribution in the AKI and non AKI groups.

The highest RIFLE class was obtained using serum creatinine in $98.6 \%$ of patients and using urine output in $1.4 \%$ of patients ( 3 patients only). In $76.1 \%$ of the patients the baseline serum creatinine was calculated using the MDRD equation because a record with previous baseline levels was not present for most of the patients. Concerning urinary output all patients except the 3 mentioned had more than $0.5 \mathrm{ml} / \mathrm{Kg} / \mathrm{h}$ of diuresis. In all other patients what gave the RIFLE class of Risk, Injury or Failure was the increase from the basal level of creatinine to the maximum level of creatinine achieved during the entire length in ICU according to the criteria defined in table 1[7].

AKI occurred in 217 patients (50\%) but only 8\% developed class F. No differences in age, gender, type of injury, mechanism of injury, TRISS, SAPS II, incidence of different body regions involved or RTS were found between patients with and without AKI. The severity of trauma, assessed by ISS, was higher in the AKI group $(28.4 \pm 11.8$ vs. $26.21 \pm 10.9, \mathrm{p}=0.045)$. In the subgroup of patients with AKI, $47 \%$ had a maximum RIFLE class of Risk, 36\% had Injury, and $17 \%$ had Failure.

In terms of outcomes, none of the patients in our study required renal replacement therapy during ICU or hospital stay, and no patients reached the RIFLE outcome classes L or E. All patients that survived returned to normal levels of creatinine and diuresis. Increasing severity of AKI was associated with a significant increase in ICU length of stay $(\mathrm{p}=0.044)$. Length of hospital stay also tended to increase with severity of AKI, but the differences had no statistical significance. We were not able to relate an increase in mortality to the severity of

Table 2 Population characteristics.

\begin{tabular}{|c|c|c|c|c|}
\hline & \multirow[b]{2}{*}{$\begin{array}{c}\text { Total } \\
(n=436)\end{array}$} & \multicolumn{2}{|c|}{ All trauma } & \multirow[b]{2}{*}{$\mathrm{p}$} \\
\hline & & $\begin{array}{c}\text { No AKI } \\
(\mathrm{n}=219,50 \%)\end{array}$ & $\begin{array}{c}\mathrm{AKI} \\
(\mathrm{N}=217,50 \%)\end{array}$ & \\
\hline \multicolumn{5}{|l|}{ Baseline characteristics } \\
\hline \multicolumn{5}{|l|}{ Gender, n (\%) } \\
\hline Male & $350(80)$ & $170(78)$ & $180(83)$ & 0.162 \\
\hline Female & $86(20)$ & $49(22)$ & $37(17)$ & \\
\hline Age, median (IQR) & $37(23-55)$ & $37(22-52)$ & $37(24-55)$ & 0.814 \\
\hline ISS, mean (SD) & $27.3(11.4)$ & $26.2(10.9)$ & $28.4(11.8)$ & 0.045 \\
\hline TRISS, mean (SD) & $71.2(27.1)$ & $70.1(27.2)$ & $68.1(28.00)$ & 0.414 \\
\hline SAPS II, median (IQR) & $36(26-45)$ & $34(25-45)$ & $38(28-46)$ & 0.288 \\
\hline Intracranial hypertension, $\mathrm{n}(\%)$ & $254(58)$ & $167(76)$ & $87(40)$ & $<0.001$ \\
\hline \multicolumn{5}{|l|}{ Trauma, n (\%) } \\
\hline Head & $410(94)$ & $205(94)$ & $205(95)$ & 0.704 \\
\hline Thorax & $216(50)$ & $107(49)$ & $109(50)$ & 0.775 \\
\hline Abdomen & $54(12)$ & $22(10)$ & $32(15)$ & 0.136 \\
\hline Pelvis and limbs & $202(46)$ & $94(43)$ & $108(50)$ & 0.152 \\
\hline Spinal & $17(4)$ & $6(3)$ & $11(5)$ & 0.209 \\
\hline Renal trauma, n(\%) & $11(2.5)$ & $5(2.3)$ & $6(2.8)$ & 0.748 \\
\hline \multicolumn{5}{|l|}{ Outcomes } \\
\hline ICU LOS, median (IQR) & $7(3-13)$ & $5(2-11)$ & $9(5-16)$ & $<0.001$ \\
\hline Hospital LOS, median (IQR) & $13(5-24)$ & $10(3-19)$ & $16(9-29)$ & $<0.001$ \\
\hline ICU mortality, n (\%) & $97(22)$ & $61(28)$ & $36(17)$ & 0.005 \\
\hline \multicolumn{5}{|l|}{ Hospital Mortality (n\%) } \\
\hline Overall & $129(30)$ & $82(37)$ & $47(22)$ & $<0.001$ \\
\hline Early & $57(13)$ & $45(21)$ & $12(6)$ & $<0.001$ \\
\hline Late & $72(17)$ & $37(22)$ & $35(18)$ & 0.315 \\
\hline
\end{tabular}




\begin{tabular}{|c|c|c|c|c|}
\hline & \multicolumn{3}{|c|}{ Only AKI patients } & \multirow[b]{2}{*}{ p } \\
\hline & $\begin{array}{c}\text { Risk } \\
(\mathrm{n}=102,24 \%)\end{array}$ & $\begin{array}{c}\text { Injury } \\
(\mathrm{n}=78,18 \%)\end{array}$ & $\begin{array}{c}\text { Failure } \\
(n=37,8 \%)\end{array}$ & \\
\hline \multicolumn{5}{|l|}{ Baseline characteristics } \\
\hline \multicolumn{5}{|l|}{ Gender, n (\%) } \\
\hline Male & $88(86)$ & $65(83)$ & $27(73)$ & 0.182 \\
\hline Female & $14(14)$ & $13(17)$ & $10(27)$ & \\
\hline Age, median (IQR) & $40(24-55)$ & $36(22-57)$ & $35(28-53)$ & 0.626 \\
\hline ISS, mean (SD) & $27.7(10.96)$ & $29.0(13.1)$ & $28.9(11.7)$ & 0.736 \\
\hline TRISS, mean (SD) & $69.2(27.5)$ & $67.00(28.9)$ & $66.6(28.4)$ & 0.831 \\
\hline SAPS II, median (IQR) & $38(15-75)$ & $38(31-48)$ & $36(26-42)$ & 0.299 \\
\hline \multicolumn{5}{|l|}{ Trauma, n (\%) } \\
\hline Head & $98(96)$ & $75(95)$ & $32(87)$ & - \\
\hline Thorax & $49(48)$ & $36(46)$ & $24(65)$ & 0.143 \\
\hline Abdomen & $18(18)$ & $8(10)$ & $6(16)$ & 0.368 \\
\hline Pelvis and limbs & $49(48)$ & $36(46)$ & $23(62)$ & 0.246 \\
\hline Spinal & $5(5)$ & $6(8)$ & $0(0)$ & - \\
\hline Renal trauma, n(\%) & $5(4.9)$ & $0(0)$ & $1(2.7)$ & - \\
\hline \multicolumn{5}{|l|}{ Outcomes } \\
\hline ICU LOS, median (IQR) & $8(5-12)$ & $9(7-17)$ & $13(7-19)$ & $<0.044$ \\
\hline Hospital LOS, median (IQR) & $15(7-30)$ & $17(9-24)$ & $18(9-33)$ & $<0.696$ \\
\hline ICU mortality, n (\%) & $15(15)$ & $14(18)$ & $7(19)$ & 0.775 \\
\hline \multicolumn{5}{|l|}{ Hospital Mortality (n\%) } \\
\hline Overall & $24(23)$ & $15(19)$ & $8(22)$ & 0.786 \\
\hline Early & $7(7)$ & $2(3)$ & $3(8)$ & - \\
\hline Late & 17 (19) & $13(18)$ & $5(15)$ & 0.885 \\
\hline
\end{tabular}

AKI. Overall trauma patient mortality was 30\% and was significantly higher for patients without AKI. Regarding late mortality, no differences were found between the AKI and No AKI groups (18\% versus $22 \%, \mathrm{p}=0.315)$. When stratified by RIFLE category the crude mortality was $23 \%$ for Risk, $19 \%$ for Injury, and 22\% for Failure.

To better understand mortality distribution we divided the mortality into early (less than two days) and late categories. We found a significantly higher proportion of mortalities in the first two days in the group of patients without AKI (79\% of early deaths are in the No AKI group). We also found a significantly higher incidence of intracranial hypertension and a higher proportion of mortality due to intracranial hypertension in the No AKI group of patients.

\section{Discussion}

Our main finding was that AKI (defined using RIFLE criteria) was common in ICU trauma patients. Recently, Bagshaw et al. suggested that trauma admissions to the ICU are frequently complicated by early AKI, with an incidence of about 18\% [12]. Despite their use of the RIFLE classification, comparison of the results of that study and this one is difficult. That study only looked at early AKI while this study looked at the full range of AKI and found an even higher AKI incidence (50\%). RIFLE criteria have recently been used to define AKI in a variety of ICU patients, and in accordance with other studies, we also found that RIFLE allows for the identification and classification of a significant proportion of critically injured patients as having some degree of AKI $[8,10,12,13]$. We found that the development of AKI was related to the severity of illness, in the case of trauma assessed by the ISS, but not to age, gender, type of trauma or mechanism of injury. A recent paper by Yuan finds an incidence of AKI defined also by RIFLE in only $10.7 \%$ of all road traffic accidents. Yuan describes a cohort of trauma patients admitted only after road traffic accident and that had also minor traumas [19]. We describe a cohort of severely injured trauma patients admitted to the ICU. That helps explain the differences in incidence of AKI between our study and the two studies that also use RIFLE criteria in trauma patients.

A second important finding was that the development of AKI, defined by the RIFLE criteria, had consequences in terms of outcome, namely an increase in ICU and 
hospital LOS, but did not result in the need for renal replacement therapies (RRT) in any of our patients. Besides we found AKI in $50 \%$ of patients, most of the patients had classes Risk and Injury and only $8 \%$ had Failure. Most of the studies that address AKI in trauma suggest that AKI is rare and that the use of renal replacement therapy is even rarer and usually related to the development of severe sepsis [18]. In this paper Brown et al. find a need for RRT in only $0.2 \%$ of trauma patients. One result that is probably difficult to generalize to other ICU or country is the absence of renal replacement therapy. Indication and timing for RRT varies in different countries and institutions and our result probably reflect also local policies. The small number of patients (37) that were classified as Failure according to RIFLE criteria might also have limited the study of RRT outcome.

Finally we did not find a relation between AKI (and the R, I and F RIFLE categories) and mortality. Early mortality for non AKI patients was dependent on the severity of the head injury related to the development of intracranial hypertension. That was not a surprise as we know that the main causes of death in trauma are bleeding and head trauma. We were however surprised by the absence of relationship between later mortality and AKI. We can hypothesize that the reasons might be related to an improved pre-hospital and emergency room care or less co-morbidity in the population studied or less sepsis in the ICU population compared to other studies. However we do not have data in the present study to confirm those hypotheses.

The retrospective nature of this study is a limitation, especially since we did not have any pre-ICU data in most of the patients, such as previous creatinine values. In addition, this study was performed at a single level I trauma centre and a single ICU and the case mix might affect the detection of outcomes of interest and the generalization of the conclusion. However concerning the capture of outcome of interest - AKI - we consider that this cohort is highly representative as it is constituted by the most severe patients expected to progress to AKI. Studies have suggested that AKI in trauma develops late and as a complication of multiple organ dysfunction syndromes $[18,26]$. We again consider that the ICU setting would be most appropriate to capture AKI. Possibly we could have overestimates the incidence of AKI in our cohort compared to a cohort of less severe patients. The incidence of AKI could have been lower in a different ICU with different patient severity. However considering that our case mix of very severe trauma patients admitted to ICU is the most appropriate to study AKI we would not expect to see a different relation between AKI and mortality in a less severe cohort of patients.

\section{Conclusions and further research}

In a population of severe trauma patients admitted to the ICU, AKI was frequent and associated with an increase in ICU and hospital stay but not with mortality. Further research, with a prospective design addressing etiology and time to AKI is needed to help in the discussion of the relationship between AKI and mortality in severe trauma patients.

\section{Acknowledgements}

Preliminary results of this study were presented at the 21st ESICM Annual Congress, 2008.

\section{Author details}

'Unidade de Cuidados Intensivos Polivalente, Hospital de Santo António, Centro Hospitalar do Porto, 4099 - 001 Porto, Portugal. ${ }^{2}$ Serviço de Bioestatística e Informática Médica, Faculdade de Medicina da Universidade do Porto, Alameda Professor Hernâni Monteiro, 4200-319 Porto, Portugal. ${ }^{3}$ CINTESIS (Centro de Investigação em Tecnologias da Saúde e Sistemas de Informação em Saúde), Serviço de Bioestatística e Informática Médica, Faculdade de Medicina da Universidade do Porto, Alameda Professor Hernâni Monteiro. 4200-319 Porto, Portugal.

\section{Authors' contributions}

EG and RA carried out the design of the study, acquisition of data, analysis and interpretation of data and drafted the manuscript. CD participated in the design of the study and performed the statistical analysis. RA and ACP participated in the design of the study and helped to draft the manuscript. All authors read and approved the final manuscript.

\section{Competing interests}

The authors declare that they have no competing interests.

\section{Received: 11 September 2009}

Accepted: 5 January 2010 Published: 5 January 2010

\section{References}

1. Bellomo R, Kellum JA, Ronco C: Defining acute renal failure: physiological principles. Intensive care Med 2004, 30:33-37.

2. Mehta RL, Pascual MT, Soroko S, Savage BR, Himmelfarb J, Ikizler TA, Paganini EP, Chertow GM: Spectrum of acute renal failure in the intensive care unit: the PICARD experience. Kidney Int 2004, 66:1613-1621.

3. Metnitz PG, Krenn CG, Steltzer H, Lang T, Ploder J, Lenz K, Le Gall JR, Druml W: Effect of acute renal failure requiring renal replacement therapy on outcome in critically ill patients. Crit Care Med 2002, 30:20512058.

4. Uchino S, Kellum JA, Bellomo R, Doig GS, Morimatsu H, Morgera S, Schetz M, Tan I, Bouman C, Macedo E, Gibney N, Tolwani A, Ronco C: Acute renal failure in critically ill patients: a multinational, multicenter study. JAMA 2005, 294:813-818.

5. Levy MM, Macias WL, Vincent JL, Russell JA, Silva E, Trzaskoma B, Williams MD: Early changes in organ function predict eventual survival in severe sepsis. Crit Care Med 2005, 33:2194-2201.

6. Brivet $F$, Kleinknecht $D$, Loirat $P$, Landais $P J$ : Acute renal failure in intensive care units-causes, outcome, and prognosis factors of hospital mortality. A prospective, multicenter study. French Study Group on Acute Renal Failure. Crit Care Med 1996, 24:192-198.

7. Bellomo R, Ronco C, Kellum JA, Mehta RL, Palevsky P: Acute renal failure definition, outcome measures, animal models, International Consensus Conference of the Acute Dialysis Quality Initiative (ADQI) Group. Crit Care 2004, 8:R204-212.

8. Abosaif NY, Tolba YA, Heap M, Russell J, El Nahas AM: The outcome of acute renal failure in the intensive care unit according to RIFLE: Model application, sensitivity, and predictability. Am J Kidney Dis 2005, 46:10381048.

9. Cruz DN, Bolgan I, Perazella MA, Bonello M, Cal M, Corradi V, Polanco N, Ocampo C, Nalesso F, Piccinni P, Ronco C: North East Prospective Hospital 
Renal Outcome Survey on Acute Kidney Injury (NEiPHROS-AKI) Targeting the problem with the RIFLE criteria. Clin J Am Soc Nephrol 2007, 2:418-425.

10. Uchino S, Bellomo R, Goldsmith D, Bates S, Ronco C: An assessment of the RIFLE criteria for acute renal failure in hospitalized patients. Crit Care Med 2006, 34:1913-1917.

11. Jenq CC, Tsai MH, Tian YC, Lin CY, Yang C, Liu NJ, Lien JM, Chen YC, Fang JT, Chen PC, Yang CW: RIFLE classification can predict short-term prognosis in critically ill cirrhotic patients. Intensive Care Med 2007, 33(11):1921-30.

12. Bagshaw SM, George C, Gibney RT, Bellomo R: A multi-center evaluation of early acute kidney injury in critically ill trauma patients. Ren Fail 2008, 30:581-589.

13. Lopes JA, Jorge S, Neves FC, Caneira M, da Costa AG, Ferreira AC, Prata MM: An assessment of the rifle criteria for acute renal failure in severely burned patients. Nephrol Dial Transplant 2007, 22:285.

14. Bell M, Liljestam E, Granath F, Fryckstedt J, Ekbom A, Martling CR: Optimal follow-up time after continuous renal replacement therapy in actual renal failure patients stratified with the RIFLE criteria. Nephrol Dial Transplant 2005, 20:354-360.

15. Hoste EA, Clermont G, Kersten A: RIFLE criteria for acute kidney injury are associated with hospital mortality in critically ill patients: A cohort analysis. Crit Care 2006, 10:R73-R83.

16. Kuitunen A, Vento A, Suojaranta-Ylinen R, Pettilä V: Acute renal failure after cardiac surgery: Evaluation of the RIFLE classification. Ann Thorac Surg 2006, 81:542-546.

17. Vivino G, Antonelli M, Moro ML, Cottini F, Conti G, Bufi M, Cannata F, Gasparetto A: Risk factors for acute renal failure in trauma patients. Intensive Care Med 1998, 24:808-814.

18. Brown CV, Dubose JJ, Hadjizacharia P, Yanar H, Salim A, Inaba K, Rhee P, Chan L, Demetriades D: Natural History and Outcomes of Renal Failure after Trauma. J Am Coll Surg 2008, 206:426-431.

19. Yuan F, Hou FF, Wu Q, Chen PY, Xie D, Zhang X: Natural history and impact on outcomes of acute kidney injury in patients with road traffic injury. Clin Nephrol 2009, 71(6):669-679.

20. Antunes R, Graça A, Santos M, Dias C, Carneiro A, Gomes El: RIFLE criteria in critically injured patients - is there a predictive ability?. Intensive care Med 2007, 34:S40.

21. Gomes E, Araújo R, Carneiro A, Dias C, Lecky FE, Costa-Pereira A: Mortality distribution in a trauma system: From data to Health policy recommendations. Eur J Trauma Emerg Surg 2008, 34:561-569.

22. Boyd CR, Tolson MA, Copes WS: Evaluating trauma care: the TRISS method. Trauma Score and the Injury Severity Score. J Trauma 1987, 27(4):370-8.

23. K/DOQI clinical practice guidelines for chronic kidney disease: evaluation, classification, and stratification. Am J Kidney Dis 2002, 39(1): S1-S266.

24. Levey AS, Bosch JP, Lewis JB, Greene T, Rogers N, Roth D: A more accurate method to estimate glomerular filtration rate from serum creatinine: a new prediction equation. Modification of Diet in Renal Disease Study group. Ann Intern Med 1999, 130:461-470.

25. Bagshaw SM, Uchino S, Cruz D, Bellomo R, Morimatsu H, Morgera S, Schetz M, Tan I, Bouman C, Macedo E, Gibney N, Tolwani A, Oudemans-van Straaten HM, Ronco C, Kellum JA: A comparison of observed versus estimated baseline creatinine for determination of RIFLE class in patients with acute kidney injury. Nephrol Dial Transplant 2009, 24(9):2739-2744

26. Gasparovic V, Radonic R, Gjurasin M, Gasparovic H, Ivanovic D, Merkler M, Jelic I: Aetiology and outcome of acute renal failure secondary to war related trauma and infectious disease in Croatia. Nephrol 2007, 3(2):155158.

doi:10.1186/1757-7241-18-1

Cite this article as: Gomes et al: Acute kidney injury in severe trauma assessed by RIFLE criteria: a common feature without implications on mortality?. Scandinavian Journal of Trauma, Resuscitation and Emergency Medicine 2010 18:1. 